\title{
Intravitreal Ranibizumab Monotherapy or Combined with Laser for Diabetic Macular Edema (OCT guided study)
}

\author{
Hassan Mohammed Higazy, Abdalla Mohamed Alamine Abdalla, Mahmoud Abd Elhaleem Ali* \\ Department of Ophthalmology, Faculty of Medicine- Aswan University \\ *Correspondence to: Mahmoud Abd Elhaleem Ali; Mobile: (+20)01066799990, \\ Email: Mahmoud.abdelhalim@aswu.edu.eg
}

\begin{abstract}
Background: Diabetic retinopathy (DR) is the most frequent ocular complication of diabetes mellitus and the leading cause of blindness in the working age population in developing countries.

Objective: The aim of this study was to compare central macular thickness using optical coherence tomography (OCT) between Ranibizumab $0.5 \mathrm{mg}$ monotherapy over Ranibizumab $0.5 \mathrm{mg}$ combined with laser based on mean average change in best-corrected visual acuity (BCVA) over 6 months in diabetic macular edema (DME).

Patients and methods: The study was carried out on forty eyes of patients aged 30-75 years old, with type 1 or 2 diabetes mellitus and have visual impairment due to DME. The patients were selected from the Outpatient Ophthalmology Clinic of Aswan University Hospital.

Results: Both groups achieved improvement of visual acuity and reduction of the macular thickness but the effect was more pronounced and long lasting in the combined therapy group.

Conclusion: The use of more than one line of treatment in combination for patients with diffuse DME could provide more sustained results with the need for less frequent injections and decreasing the recurrence or persistence rate of DME.
\end{abstract}

Keywords: Intravitreal Ranibizumab Monotherapy, Diabetic Macular Edema, BCVA, OCT.

\section{INTRODUCTION}

Diabetic macular edema (DME) is the main cause for decreased visual acuity in patients with $\mathrm{DM}^{(\mathbf{1})}$. Nearly half of those developing DME will lose two or more lines of visual acuity within two years. DME with visual impairment affects approximately $1-3 \%$ of diabetic population worldwide (2).

Focal/grid laser photocoagulation (laser), the standard of care for DME since1985, was shown by the Early Treatment Diabetic Retinopathy Study (ETDRS) to reduce the risk for significant vision loss by $50 \%$, but complete cessation of vision loss and/or improvements in visual acuity are rarely observed ${ }^{(3)}$.

Based on studies, the levels of vascular endothelial growth factors (VEGF) are increased in the retina and vitreous of eyes with DR and DME. Inhibiting VEGF may provide an alternative therapeutic approach for this condition (4). AntiVEGF agents have been reported to be efficacious in treating DME (5). Among the anti- VEGF therapeutics, ranibizumab (RBZ) is an antibody fragment with high binding affinity for VEGF-A, specifically developed for intraocular use commonly used as an intravitreal therapeutic option in treating diabetic macular edema resulting in improving the central macular thickness and best-corrected visual acuity (BCVA) ${ }^{(6)}$. Ranibizumab currently approved by the US Food and Drug Administration for intraocular use, the infusion of $0.5 \mathrm{mg}$ of Ranibizumab into the vitreous cavity has been performed without significant intraocular toxicity. Therefore, it is of interest to uncover which treatment modality is more effective and safe for DME ${ }^{(7)}$.
Several studies on anti-VEGF agents for DME suggested that VEGF inhibitors are effective in treating DME, but in these cases Ranibizumab was analyzed together with other VEGF inhibitors, including pegaptanib, aflibercept, and bevacizumab (8).

\section{AIM OF THE STUDY \\ The aim of this study was to compare central macular thickness using optical coherence tomography (OCT) between Ranibizumab $0.5 \mathrm{mg}$ monotherapy over Ranibizumab $0.5 \mathrm{mg}$ combined with laser based on mean average change in best- corrected visual acuity (BCVA) over 6 months in diabetic macular edema (DME). \\ PATIENTS AND METHODS \\ Patients \\ Randomized prospective interventional study. The study was carried out on forty eyes of patients aged 30-75 years, with type 1 or 2 diabetes mellitus and had visual impairment due to DME. The patients were selected from the Outpatient Ophthalmology Clinic of Aswan University Hospital.}

\section{Ethical consideration and Written informed consent}

An approval of the study was obtained from Aswan University Academic and Ethical Committee. Every patient signed an informed written consent for acceptance of the operation. 


\section{Methods:}

Forty eyes was assigned to one of the following 2 groups according to the regimen used in the management of diabetic macular edema (each group consists of 20 eyes):

- Group A: 20 eyes who randomized to be injected with $0.5 \mathrm{mg}$ ranibizumab $(0.1 \mathrm{ml})$ at baseline, $1 \mathrm{st}$ month, and 3rd month.

- Group B: 20 eyes who randomized to be injected with $0.5 \mathrm{mg}$ ranibizumab at baseline, 1st month, and 3rd month followed with macular grid argon laser photocoagulation three weeks after the 1 st injection.

\section{History taking:}

- Age.

- Duration of diabetes, any systemic disease and drug intake.

- Type, duration and onset of diminution of vision.

- Previous ocular surgery or interventions.

\section{Assessment of uncorrected and best corrected visual acuity:}

- All visual acuity results were transformed to the common logarithm of the minimum angle of resolution (Log MAR).

Slit-lamp examination: To assess anterior segment for any abnormalities (cataract, corneal opacities).

\section{Intraocular pressure (IOP) measurement: using} Goldman's applanation tonometry.

FFA: A colored photo of the fundus was taken at first prior to injection.

Macular OCT: Macular OCT was done to detect the presence of retinal thickening, cystoid macula edema, hard exudates and vitreoretinal interface.

Baseline central retinal characteristics were analyzed by OCT through a dilated pupil.

Retinal thickness was defined as the distance between the inner retinal surface defined as the interface between the dark vitreous and the bright reflection of ILM and the outer retinal surface defined as the inner surface of bright RPE/Bruch's membrane interface. Also, scans were graded for the presence of specific morphological patterns of macular edema.

Follow up: Visual acuity as $\log$ MAR value measured with optical coherence tomography (OCT). Moreover, intraocular pressure (IOP) was assessed at baseline, 1, 3 and 6 months post-injection.

\section{Operative technique:}

- Intravitreal injection was given at the operating theatre using aseptic technique (Figure 1). All

patients received 3 injections at baseline, 1 and 3rd months.

- Topical anesthesia by Benoxinate HCL $0.4 \%$ eye drops.

- Ocular sterilization with betadine eye drops 5\% and draping.

- Insertion of a lid speculum.

- Ranibizumab (Lucentis) $0.5 \mathrm{mg} / 0.05 \mathrm{~mL}$ was injected through pars plana with a 28 -gauge needle $4 \mathrm{~mm}$ behind the limbus in phakic patients and $3.5 \mathrm{~mm}$ in pseudophakic patients.

- The patient is asked to look 90 degrees away from the injection site.

- The needle was inserted in the marked site in a smooth and single motion, aiming for the midvitreous cavity.

- Securing the removal of the syringe by a tip of cotton swab to prevent reflux of Lucentis or vitreous from the injection site.

- Central retinal artery perfusion and IOP were assessed just after injection; paracentesis was done if IOP was markedly increased.

- Removal of eye speculum.

- Application of eye ointment (combination of antibiotic and steroid).

- Eye patching by sterile dressing.

- Topical antibiotic moxifloxacin $5 \mathrm{mg} / \mathrm{ml}$ was prescribed for 5 days.
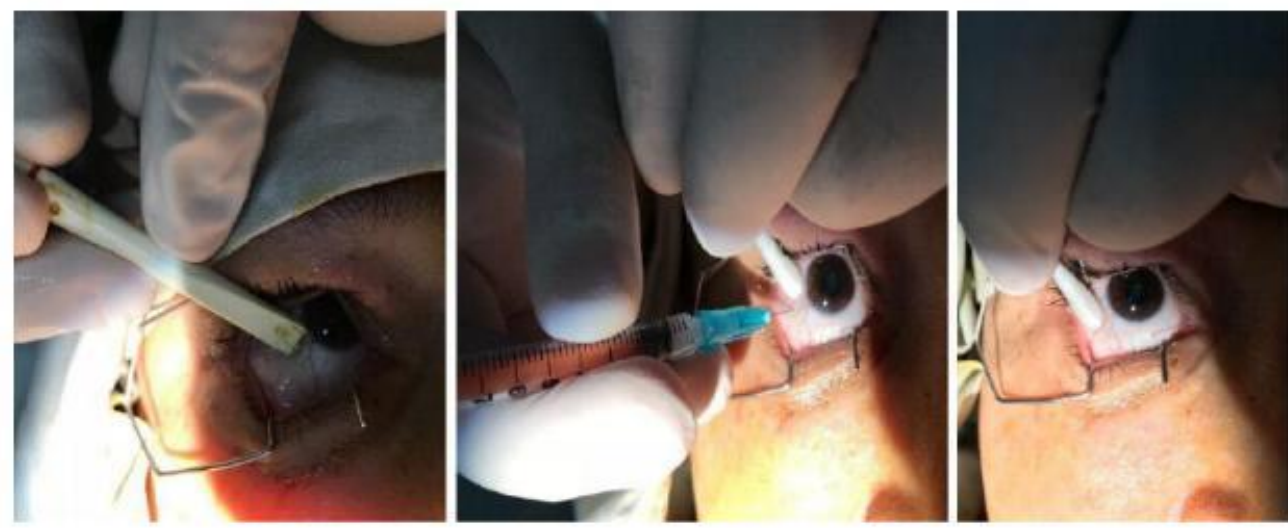

Figure (1): Intravitreal injection. 


\section{Post-operative:}

The patients were monitored for potential injection related complications by measurement of BCVA, IOP and evaluation of anterior segment and posterior segment at 1, 3 and 7 days after injection.

The anatomical and functional responses to treatment were followed up at 1 and $3 \& 6$ months after baseline injection.

\section{Statistical analysis}

Recorded data were analyzed using the statistical package for social sciences, version 20.0 (SPSS Inc., Chicago, Illinois, USA). Quantitative data were expressed as mean \pm standard deviation (SD). Qualitative data were expressed as frequency and percentage. The following tests were done:

- Independent-samples t-test of significance was used when comparing between two means.

- Paired sample t-test of significance was used when comparing between related samples.

- Chi-square $\left(\mathrm{x}^{2}\right)$ test of significance was used in order to compare proportions between qualitative parameters.

- The confidence interval was set to $95 \%$ and the margin of error accepted was set to 5\%. So, the pvalue was considered significant as the following:

- Probability (P-value)

P-value $<0.05$ was considered significant.

- P-value $<0.001$ was considered as highly significant.

- P-value >0.05 was considered insignificant.

\section{RESULTS}

The demographic data of the patients included in the study groups are shown in table 1 .

The study was carried out on forty eyes of patients aged 30-75 years old, with type 1 or 2 diabetes mellitus and have visual impairment due to DME were enrolled in this study. There were $20 \%$ male and $80 \%$ female patients in Group A (IR group) while in Group B (combined group) there were 35\% male and $65 \%$ female patients.
Table (1): A Comparison between groups according to demographic data.

\begin{tabular}{|c|c|c|c|c|}
\hline $\begin{array}{l}\text { Demographic } \\
\text { data }\end{array}$ & $\begin{array}{l}\text { Group } \\
\text { A } \\
(\mathbf{n}=20)\end{array}$ & $\begin{array}{l}\text { Group } \\
\text { B } \\
(n=20)\end{array}$ & $t / x 2 \#$ & $\begin{array}{l}\text { p- } \\
\text { valu }\end{array}$ \\
\hline $\begin{array}{l}\text { Age (years) } \\
\text { Mean } \pm \text { SD } \\
\text { Range }\end{array}$ & $\begin{array}{c}55.75 \pm \\
4.66 \\
47-68\end{array}$ & $\begin{array}{c}58.35 \pm \\
5.14 \\
45-65\end{array}$ & 2.81 & 0.102 \\
\hline $\begin{array}{l}\text { Sex } \\
\text { Female } \\
\text { Male }\end{array}$ & $\begin{array}{c}16 \\
(80.0 \%) \\
4 \\
(20.0 \%) \\
\end{array}$ & $\begin{array}{c}13 \\
(65.0 \%) \\
7 \\
(35.0 \%) \\
\end{array}$ & $\begin{array}{c}1.129 \\
\#\end{array}$ & 0.288 \\
\hline
\end{tabular}

t-Independent Sample t-test; $\# \mathrm{x}^{2}$ : Chi-square test $\mathrm{p}$ value $>0.05 \mathrm{NS} ; *$ p-value $<0.05 \mathrm{~S} ; * *$ p-value $<0.001$ HS.

This table showed no statistically significant difference between groups according to demographic data.

\section{Changes in visual acuity over the follow up period:}

Visual acuity measured as log MAR values in group " $A$ ", when comparing the baseline visual acuity with that at the end of follow-up period, there was a significant improvement in vision and some patients achieved improvement of two lines at the end of six months. In group " $\mathrm{B}$ ", there was a significant improvement in vision when comparing the baseline reading with the six months reading with an average gain in visual acuity of two or more lines. Vision gain was achieved in both groups throughout the follow-up period with no significant difference between them but the effect was more pronounced and long lasting in the combined group (group B) than in the IR group (group A) (Table 2).

Table (2): A Comparison between groups according to BCVA.

\begin{tabular}{|c|c|c|c|l|l|}
\hline & BCVA & Group A $(\mathbf{n}=\mathbf{2 0})$ & Froup B $(\mathbf{n = 2 0})$ & t-test & p-value \\
\hline Before & Mean \pm SD & $0.81 \pm 0.08$ & $0.78 \pm 0.08$ & 0.908 & 0.347 \\
& Range & $0.6-0.9$ & $0.6-0.9$ & & \\
\hline $\mathbf{1}^{\text {st }}$ month after injection & Mean \pm SD & $0.64 \pm 0.10$ & $0.67 \pm 0.09$ & 0.712 & 0.404 \\
& Range & $0.5-0.8$ & $0.5-0.8$ & & \\
\hline $3^{\text {rd }}$ month after injection & Mean \pm SD & $0.58 \pm 0.07$ & $0.62 \pm 0.08$ & 1.353 & 0.493 \\
& Range & $0.5-0.7$ & $0.5-0.8$ & & \\
\hline $6^{\text {th }}$ month after injection & Mean \pm SD & $0.53 \pm 0.05$ & $0.57 \pm 0.07$ & 0.651 & 0.36 \\
& Range & $0.5-0.6$ & $0.4-0.7$ & & \\
\hline
\end{tabular}

$\mathrm{t}$-Independent Sample t-test; $\mathrm{p}$-value > $0.05 \mathrm{NS}$

This table showed no statistically significant difference between groups according to BCVA. 
Table (3): A Comparison between before with other category according to BCVA in each group.

\begin{tabular}{|l|l|l|l|l|l|l|}
\hline \multirow{2}{*}{ BCVA } & \multicolumn{2}{|l|}{ Group A (n=20) } & \multicolumn{3}{l|}{ Group B (n=20) } \\
\cline { 2 - 7 } & Mean \pm SD & Mean Diff. & p-value & Mean \pm SD & Mean Diff. & p-value \\
\hline Before & $0.81 \pm 0.08$ & & & $0.78 \pm 0.08$ & & \\
\hline 1st month after injection & $0.64 \pm 0.10$ & 0.17 & $<0.001^{* *}$ & $0.67 \pm 0.09$ & 0.12 & $<0.001^{* *}$ \\
\hline 3rd month after injection & $0.58 \pm 0.07$ & 0.23 & $<0.001^{* *}$ & $0.62 \pm 0.08$ & 0.16 & $<0.001^{* *}$ \\
\hline 6th month after injection & $0.53 \pm 0.05$ & 0.28 & $<0.001^{* *}$ & $0.57 \pm 0.07$ & 0.22 & $<0.001^{* *}$ \\
\hline
\end{tabular}

t-Paired Sample t-test $\quad *$ p-value $<0.05 \mathrm{~S} ; * *$ p-value $<0.001 \mathrm{HS}$

This table showed statistically significant difference between before with other category according to BCVA in each group.

\section{Intraocular pressure (IOP):}

The IOP did not increase to a higher levels requiring treatment in both groups.

Table (4): A Comparison between groups according to IOP.

\begin{tabular}{|l|c|c|c|c|}
\hline IOP & Group A $(\mathbf{n = 2 0})$ & Group B (n=20) & t-test & p-value \\
\hline Before & & & & \\
Mean \pm SD & $14.60 \pm 1.64$ & $15.85 \pm 2.01$ & 1.662 & 0.372 \\
Range & $12-18$ & $13-19$ & \\
\hline 1st month after injection & $14.85 \pm 1.66$ & $16.35 \pm 1.95$ & 1.835 & 0.127 \\
Mean \pm SD & $12-18$ & $13-20$ & \\
Range & $15.15 \pm 1.60$ & $16.55 \pm 1.76$ & 1.284 & 0.195 \\
\hline 3rd month after injection & $12-18$ & $14-20$ & & \\
Mean \pm SD & $15.30 \pm 1.53$ & $16.90 \pm 1.68$ & 0.927 & 0.171 \\
Range & $12-18$ & $14-20$ & & \\
\hline 6th month after injection & & & & \\
Mean \pm SD & & & & \\
Range & & & & \\
\hline
\end{tabular}

t-Independent Sample t-test; p-value >0.05 NS

This table showed no statistically significant difference between groups regarding IOP.

Table (5): A Comparison between before with other category according to IOP in each group

\begin{tabular}{|l|c|l|l|l|l|l|}
\hline \multirow{2}{*}{ IOP } & \multicolumn{2}{|c|}{ Group A (n=20) } & \multicolumn{2}{|c|}{ Group B (n=20) } \\
\cline { 2 - 7 } & Mean \pm SD & $\begin{array}{l}\text { Mean } \\
\text { Diff. }\end{array}$ & $\begin{array}{l}\text { p- } \\
\text { value }\end{array}$ & Mean \pm SD & $\begin{array}{l}\text { Mean } \\
\text { Diff. }\end{array}$ & p-value \\
\hline Before & $14.60 \pm 1.64$ & & & $15.85 \pm 2.01$ & & \\
\hline $\begin{array}{l}\text { 1st month after } \\
\text { injection }\end{array}$ & $14.85 \pm 1.66$ & -0.25 & $0.044 *$ & $16.35 \pm 1.95$ & -0.50 & $0.021^{*}$ \\
\hline $\begin{array}{l}\text { 3rd month after } \\
\text { injection }\end{array}$ & $15.15 \pm 1.60$ & -0.55 & $0.032 *$ & $16.55 \pm 1.76$ & -0.70 & $0.009 *$ \\
\hline $\begin{array}{l}\text { 6th month after } \\
\text { injection }\end{array}$ & $15.30 \pm 1.53$ & -0.70 & $0.029 *$ & $16.90 \pm 1.68$ & -1.05 & $<0.001 * *$ \\
\hline
\end{tabular}

t-Paired Sample t-test $\quad *$ p-value $<0.05 \mathrm{~S} ; * *$ p-value $<0.001 \mathrm{HS}$.

This table showed statistically significant difference between before with other category regarding IOP in each group. 


\section{Adverse effects:}

- Persistence of macular edema was responsible for the deterioration of the visual acuity in three patients one in group B and two in group A.

- Cataract formation was observed in two patient in group B at the end of follow-up period and scheduled for cataract surgery.

- One case of epiretinal membrane occurred in the group A.

\section{DISCUSSION}

Hence, it was the aim of the current study to evaluate functional and morphological outcomes in the eyes with DME treated with ranibizumab and immediate grid laser therapy compared to eyes treated with intravitreal ranibizumab only.

This study showed that treatment with anti-VEGF in addition to grid laser is effective and safe in the management of DME during a period of 6 months. However, as our findings revealed that functional results in the IR + Grid laser group were slightly higher (though not statistically significant) compared to the IR treatment group in an earlier treatment phase. This suggests that focal laser therapy in the eyes with DME is justified.

Macular laser photocoagulation seems to be responsible for the improved functional and anatomical results in the combination therapy group. Laser destroys some of photoreceptors, which consume a high amount of oxygen. This will preserve and increase the oxygen supply to the inner retinal layers. Consequently, this would decrease the retinal anoxia and reduce further releases of VEGF, subsequently improving the results and reducing the recurrence rate of DME. Hence, the use of macular laser photocoagulation with intravitreal ranibizumab injection is practically more appropriate in regaining good visual and anatomical results than ranibizumab or laser alone. Wang et al. ${ }^{(9)}$ in a meta-analysis study was trying to demonstrate the efficacy of intravitreal ranibizumab injection for treatment of DME. They concluded that ranibizumab alone or combined with laser were more advantageous than laser monotherapy.

Current treatment options for DME allowed for varied and increasing of complex combinations of treatment paradigms like laser monotherapy, combination of laser therapy with anti-VEGF agents (RBZ, bevacizumab, aflibercept), anti-VEGF monotherapy and sustained-release of corticosteroid therapy (dexamethasone, either as a monotherapy or in combination with the other therapies).

Other studies, however, showed that visual acuity deteriorated by about three lines or more in about quarter of eyes with diffuse DME after macular laser photocoagulation ${ }^{(10)}$.
READ-2 is a multicenter clinical study established to compare ranibizumab with macular laser, alone or in combination, for the treatment of DME. The study found that the ranibizumab group achieved a significant gain in visual acuity compared with patients who had only laser treatment after six months of the study. It was also found that the combination therapy group didn't have statistically significant different results than the monotherapy groups (laser alone or ranibizumab alone) regarding the visual acuity changes.

The results of RESTORE study are in line and consistent with the Diabetic Retinopathy Clinical Research Network (DRCR.net) and RESOLVE trials.

The DRCR.net trial revealed that intravitreal ranibizumab injection adjunctive with macular laser treatment either prompt or deferred was significantly more efficient than laser monotherapy in restoring good visual and anatomical results in DME patients after 12 months of therapy. This trial suggested that combined treatment could provide a more potent regimen for treatment of DME, taking into consideration the multifactorial etiology of the disease ${ }^{(11)}$.

The RESOLVE trial also showed that ranibizumab yielded a fast and long-lasting improvement in visual acuity results when compared to sham in a time of one year follow-up ${ }^{(\mathbf{1 2})}$.

Some previous trials used laser therapy within one week after the first intravitreal ranibizumab injection. The accumulation of much fluid in the retinal tissues in patients suffering from diffuse macular edema may make thermal therapy more difficult, less efficient, and requiring the delivery of more laser energy than usual that could result in more visual deterioration (13). That is why in our study, we applied laser treatment three weeks after the first ranibizumab injection allowing the retina to get rid of some retinal fluid to facilitate and make the laser application more easy and efficient.

It remains to be shown if the eyes with extensive exudative material in the central macular region and reduced BCVA would profit from an individualized and more intense anti-VEGF treatment strategy, as has been suggested by others previously ${ }^{(14)}$. Our results are in agreement and in line with the previously mentioned studies concerning the anatomical and functional results. Whereas, laser therapy still the standard treatment of DME, the appearance of anti-VEGF agents have opened up a new era in the treatment of DME that could enhance, limit, or even replace thermal therapy ${ }^{(\mathbf{1 5})}$.

Both groups achieved improvement of visual acuity and reduction of the macular thickness but the effect was more pronounced and long lasting in the combined therapy group. 


\section{CONCLUSION}

In conclusion, the use of more than one line of treatment in combination for patients with diffuse DME could provide more sustained results with the need for less frequent injections and decreasing the recurrence or persistence rate of DME.

Further studies with large number of patients and longer follow-up periods are needed to evaluate the safety and efficacy profile of combination therapy for DME over a longer time span.

\section{REFERENCES}

1. Bandello F, Battaglia M, Lanzetta $P$ et al. (2010): Diabetic macular edema. Dev Ophthalmol., 47: 73-110.

2. Klein R, Klein BE, Moss SE et al. (1984): The Wisconsin epidemiologic study of diabetic retinopathy. IV. Diabetic macular edema. Ophthalmology, 91: 14641474.

3. Aiello LP, Avery RL, Arrigg PG et al. (1994): Vascular endothelial growth factor in ocular fluid of patients with diabetic retinopathy and other retinal disorders. N Engl J Med., 331: 1480-1487.

4. Shoeibi N, Ahmadieh H, Entezari M et al. (2013): Intravitreal Ranibizumab with or without triamcinolone for refractory diabetic macular edema: long-term results of a clinical trial. J Ophthalmic Vis Res., 8 (2): 99-106.

5. Stefanini FR, Arevalo JF, Maia M (2013): Ranibizumab for the management of diabetic macular edema. World J Diabetes, 4 (2): 19-26.

6. Zhang XL, Chen J, Zhang RJ et al. (2013): Intravitreal triamcinolone versus intravitreal Ranibizumab for diabetic macular edema: a metaanalysis. Int J Ophthalmol., 6 (4): 546-552.

7. Abouammoh MA (2013): Ranibizumab injection for diabetic macular edema: meta-analysis of systemic safety and systematic review. Can J Ophthalmol., 48: 317-323.

8. Virgili G, Parravano M, Menchini F et al. (2012): Antiangiogenic therapy with anti-vascular endothelial growth factor modalities for diabetic macular oedema. Cochrane Database Syst Rev., 12: CD007419.

9. Wang H, Sun X, Liu K et al. (2012): Intravitreal ranibizumab (Lucentis) for the treatment of diabetic macular edema: a systematic review and meta-analysis of randomized clinical control trials. Cur Eye Res., 37: $661-70$.

10.Lee CM, Olk RJ (1991): Modified grid laser photocoagulation for diffuse diabetic macular edema: long term visual results. Ophthalmology, 98: 1594-602.

11.EIman MJ, Bressler NM, Qin $H$ et al. (2011): Expanded 2-year follow-up of ranibizumab plus prompt or deferred laser or triamcinolone plus prompt laser for diabetic macular edema. Ophthalmology, 118: 609-14.

12. Massin P, Bandello F, Garweg J et al. (2010): Safety and efficacy of ranibizumab in diabetic macular edema (RESOLVE study): a 12-month, randomized, controlled, doublemasked, multicenter phase II study. Diabetes Care, 33: $2399-405$.

13. Comyn O, Sivaprasad S, Peto T et al. (2014): A randomized trial to assess functional and structural effects of ranibizumab versus laser in diabetic macular edema (the LUCIDATE study). Am J Ophthalmol., 157: $960-970$.

14. Mehta H, Fraser-Bell S, Yeung A et al. (2016): Efficacy of dexamethasone versus bevacizumab on regression of hard exudates in diabetic maculopathy: data from the BEVORDEX randomised clinical trial," British Journal of Ophthalmology, 10 (7): 1000-1004.

15. Ford J A, Lois N, Royle P et al. (2013): Current treatments in diabetic macular oedema: systematic review and meta-analysis. BMJ Open, 3 (3): 2269-74. 